\title{
Obesity and Body Fat Distribution: Ethnic Differences and the Role of Socio-Economic Status
}

\author{
Joanne K. Ujcic-Voortman ${ }^{\mathrm{a}}$ Griët Bos ${ }^{\mathrm{b}}$ Caroline A. Baan ${ }^{\mathrm{b}} \quad$ Arnoud P. Verhoeffa,c \\ Jacob C. Seidell ${ }^{\mathrm{d}}$ \\ a Department of Epidemiology, Documentation and Health Promotion, Public Health Service Amsterdam, Amsterdam, \\ ${ }^{\mathrm{b}}$ National Institute of Public Health and the Environment, Centre for Prevention and Health Services Research, Bilthoven, \\ ${ }^{\circ}$ Faculty of Social and Behavioural Sciences, University of Amsterdam, \\ ${ }^{d}$ Faculty of Earth and Life Sciences, VU University, Amsterdam, the Netherlands
}

\section{Keywords}

Overweight - Body mass index - Waist circumference .

Waist-to-hip ratio $\cdot$ Ethnic groups

\section{Summary}

Objective: This study investigates differences in overweight and body fat distribution between Turkish and Moroccan migrants and the ethnic Dutch population, and the contribution of socio-economic status to their higher obesity prevalence. Methods: Data were collected as part of a general health survey, in Amsterdam, the Netherlands (2004). From 1,285 adults information on physical and psychological health, lifestyle and demographic background was obtained through health interviews. In a physical examination body height and weight as well as waist and hip circumference were measured. Results: Overweight was more common among Turkish migrants and Moroccan migrant women as compared to their Dutch counterparts. Obesity prevalence rates were more than twice as high among Turkish (39.6\%) and Moroccan $(39.1 \%)$ women than among Dutch women (16.5\%). Controlling for level of education and unemployment attenuated ethnic differences in overweight. Abdominal obesity was more common among Turkish and Moroccan than among Dutch women. After controlling for BMI, migrant men had a relatively low waist circumference compared to Dutch men. Conclusion: Overweight is relatively common among Turkish and Moroccan migrants, especially women. Education and employment are relevant in explaining ethnic differences in overweight. Compared to Dutch men, migrant men seem to have a more favourable fat distribution with less abdominal fat.

\section{Introduction}

Obesity has reached epidemic proportions globally. With more than 1 billion adults being overweight and at least 300 million of them clinically obese, it is a major contributor to the global burden of chronic diseases and disability. Obesity and overweight pose a major risk for chronic diseases, including type 2 diabetes, hypertension, cardiovascular disease, and cancer [1].

Not only the extent of overweight determines the risk of overweight related complications but also the distribution of fat over the body is an important determinant of future complications. In particular, additional abdominal fat is associated with higher disease risks than additional subcutaneous fat or femoral fat, i.e. fat located at hips and thighs. Waist circumference is a better predictor of abdominal fat than BMI [2,3] and is, together with waist-to-hip ratio, closely associated with risk of myocardial infarction and coronary heart disease [4].

Migrants often have a higher risk of obesity [5, 6]. Furthermore, people from ethnic minority groups often have a relatively low socio-economic position compared to the host culture. In highly developed countries, low socio-economic status (SES) itself is also associated with higher prevalence rates of overweight and obesity [7-9]. It is unclear whether and which socio-economic factors play a role in explaining the higher obesity risk among migrants.

In Europe, migrants from Turkey and Morocco are among the largest ethnic minority groups. Turkish migrants mainly live in Germany and the Netherlands. Migrants from Morocco mainly reside in France, Belgium, and the Netherlands [10]. In Amsterdam, the Netherlands, Turkish and Moroccan migrants account for around $5 \%$ and $9 \%$ of the total population respectively. Because of the relatively high immigration figure

\section{KARGER}

Fax +497614520714

Information@Karger.de

www.karger.com (c) 2011 S. Karger GmbH, Freiburg

$1662-4025 / 11 / 0041-0053 \$ 38.00 / 0$

Accessible online at:

www.karger.com/ofa
Joanne K. Ujcic-Voortman

Department of Epidemiology, Documentation and Health Promotion

Public Health Service Amsterdam

P.O. Box 2200, 1000 CE Amsterdam, the Netherlands

Tel: +31 20 5555-428, Fax -160

jujcic@ggd.amsterdam.nl 
and high birth rate in these groups, their numbers are expected to rise in the coming years [11].

Among Turkish and Moroccan migrants in Western European societies such as the Netherlands high levels of overweight and obesity have been reported [5, 6, 10, 12, 13]. However, many studies use self-reported data on body height and weight and limited information is available on the current obesity prevalence, based on physical measurements. In addition, little is known about the effect of SES on ethnic differences in overweight and obesity prevalence, and, in particular, which socio-economic factors are relevant in explaining ethnic differences.

In this study, we aim to investigate differences in excess body weight and abdominal fat mass between Turkish and Moroccan migrants and the ethnic Dutch population. We will present prevalence rates of general, central and abdominal obesity for each ethnic group, based on physical examination. Furthermore we aim to analyse (possible) differences in the association between BMI and abdominal fat mass in these ethnic groups. Finally, this study aims to gain insight into the contribution of several indicators of SES to the high prevalence of obesity among ethnic minority groups.

\section{Material and Methods}

In 2004 a general health survey was conducted by the Public Health Service of Amsterdam in collaboration with the Dutch National Institute for Public Health and the Environment. Data obtained from this crosssectional survey in the Amsterdam population, as described earlier, were used $[14,15]$. The study sample was drawn from the municipal population register within five districts in Amsterdam. The combined population of these five districts was representative of the total Amsterdam population. To ensure sufficient numbers in each age and ethnic group, the sample was stratified by five age groups (18-34 years, 35-44 years, 45-54 years, 55-64 years, 65 years and older) and by ethnicity (Dutch, Turkish, Moroccan). Within each stratum a random sample was drawn. Selected residents ( $\geq 18$ years) were invited to participate in a health interview and health examination at a local childcare centre. All participants signed an informed consent form. The study protocol was approved by the Medical Ethical Committee of the Academic Medical Centre, University of Amsterdam.

\section{Measurements}

First, a health interview was conducted in the respondent's language of choice (i.e., Dutch, Turkish, Moroccan-Arabic, Berber or English). Translations of the questionnaire, validated by back-translation, in Turkish, Arabic, and English were available. The questionnaire covered several aspects of physical and psychological health, lifestyle, and demographic factors. Ethnicity was based on the self-reported country of birth of the respondent and his/her parents. If one of these (three) countries was Turkey or Morocco, the respondent was considered to be Turkish or Moroccan, respectively. Dutch means that both of the respondent's parents were born in the Netherlands. Several indicators of SES were assessed in the health interview, namely educational level, financial situation, net household income, and current employment status of the respondent and the household's main breadwinner. Educational level was based on the highest level of completed education and divided into three categories: 'low' (up to primary school), 'medium' (up to secondary school), and 'high' (higher professional education and university). Perceived financial situation was assessed in five categories: 'has to go into debt', 'has to use savings', 'can just get by', 'has a bit of money left', 'has a lot of money left'. Income level was considered to be below standard if the net household income was below EUR 1,350.- per month.

Second, a health examination was performed by a trained nurse. Body height and weight were measured in individuals wearing light indoor clothing, without shoes and emptied pockets. Body height was measured with a wall-mounted stadiometer to the nearest $0.5 \mathrm{~cm}$. Body weight was measured with a calibrated analogue scale to the nearest $0.5 \mathrm{~kg}$ and was adjusted for clothing weight by subtracting $1 \mathrm{~kg}$. BMI was calculated as body weight $(\mathrm{kg})$ divided by squared body height $\left(\mathrm{m}^{2}\right)$. Overweight was defined as $25 \mathrm{~kg} / \mathrm{m}^{2} \leq \mathrm{BMI}<30 \mathrm{~kg} / \mathrm{m}^{2}$, obesity as BMI $\geq 30 \mathrm{~kg} / \mathrm{m}^{2}$ [16]. Waist circumference was measured at the level midway between the lowest rib margin and the iliac crest, and the hip circumference at the widest level over the greater trochanters; both measurements were performed in duplicate. Waist-to-hip ratio was calculated as waist divided by hip circumference. Abdominal obesity was defined as waist circumference $\geq 102 \mathrm{~cm}$ for men and $\geq 88 \mathrm{~cm}$ for women, and central obesity was defined as waist-to-hip ratio $\geq 0.95$ for men and $\geq 0.80$ for women [2].

\section{Statistical Analyses}

A few respondents $(n=8)$ did not participate in the health examination. Respondents with missing values on either age, body weight, body height, waist or hip circumference $(n=44)$ were excluded from analyses. Consequently, the study population consisted of 1,285 respondents (422 Turkish, 353 Moroccan, and 510 Dutch).

To adjust for over-sampling and non-response, mean values and prevalence rates were weighted for age and sex according to the distribution in the Amsterdam population at the time of data collection (January 2004). In all univariate analyses confidence intervals were corrected for stratification using the SPSS Complex Samples procedure. After testing for normality, t-tests were used to assess ethnic differences in continuous variables while chi-square tests were used for categorical variables.

Ethnic differences in the effect of an increase in BMI on waist circumference and waist-to-hip ratio and the effect of SES on ethnic differences in BMI were analysed via linear regression analyses adjusting for age. All analyses were performed using SPSS for Windows 15.0. (SPSS Inc., Chicago, IL, USA).

\section{Results}

A total of 1,329 Amsterdam residents of Dutch, Turkish and Moroccan origin were included (479 Dutch, 453 Turks, 374 Moroccans). The response rate was $45 \%$ (Dutch $46 \%$, Turks $50 \%$, Moroccans $39 \%$ ). In table 1 the crude characteristics of the study population are shown. Turkish individuals and Moroccan women were relatively young compared to their Dutch counterparts. Educational and income level were relatively low in the Turkish and Moroccan compared to the Dutch population. Furthermore, the level of unemployment was relatively high among Turkish and Moroccan migrants.

The weighted population means for body height and weight, BMI, waist and hip circumference, and the waist-tohip ratio per ethnic group are presented in table 2. A significantly higher mean BMI was found among Turkish migrant men than ethnic Dutch men. However, although their BMI was relatively high, Turkish men did not have a higher but a lower (not significant) mean waist circumference. Moroccan 
Table 1. Demographic and socio-economic sample characteristics by sex and ethnic group

\begin{tabular}{|c|c|c|c|c|c|c|}
\hline & \multicolumn{3}{|l|}{ Men } & \multicolumn{3}{|l|}{ Women } \\
\hline & $\begin{array}{l}\text { Dutch } \\
(n=214)\end{array}$ & $\begin{array}{l}\text { Moroccan } \\
(\mathrm{n}=192)\end{array}$ & $\begin{array}{l}\text { Turkish } \\
(\mathrm{n}=196)\end{array}$ & $\begin{array}{l}\text { Dutch } \\
(\mathrm{n}=296)\end{array}$ & $\begin{array}{l}\text { Moroccan } \\
(\mathrm{n}=161)\end{array}$ & $\begin{array}{l}\text { Turkish } \\
(\mathrm{n}=226)\end{array}$ \\
\hline Mean age, years $( \pm \mathrm{SD})$ & $51.4 \pm 15.2$ & $52.4 \pm 13.2$ & $48.7 \pm 12.8$ & $52.2 \pm 15.8$ & $43.8 \pm 14.1$ & $44.1 \pm 13.9$ \\
\hline Educational level,\% low & 12.9 & 64.9 & 57.7 & 22.5 & 64.1 & 65.9 \\
\hline Income,$\%$ below standard ${ }^{\mathrm{a}}$ & 26.0 & 82.8 & 72.6 & 37.6 & 76.2 & 77.3 \\
\hline Unemployment ${ }^{\mathrm{b}}$ main breadwinner, $\%$ & 11.8 & 42.7 & 44.3 & 15.2 & 45.3 & 44.8 \\
\hline
\end{tabular}

${ }^{\text {a}}$ Net household income below EUR 1,350.- per month.

${ }^{\mathrm{b}}$ Unemployed, receiving social assistance or invalidity benefits.

Table 2. Anthropometric characteristics by sex and ethnic group: weighted population means $( \pm \mathrm{SE})$

\begin{tabular}{|c|c|c|c|c|c|c|}
\hline & \multicolumn{3}{|l|}{ Men } & \multicolumn{3}{|l|}{ Women } \\
\hline & $\begin{array}{l}\text { Dutch } \\
(n=214)\end{array}$ & $\begin{array}{l}\text { Moroccan } \\
(\mathrm{n}=192)\end{array}$ & $\begin{array}{l}\text { Turkish } \\
(\mathrm{n}=196)\end{array}$ & $\begin{array}{l}\text { Dutch } \\
(\mathrm{n}=296)\end{array}$ & $\begin{array}{l}\text { Moroccan } \\
(\mathrm{n}=161)\end{array}$ & $\begin{array}{l}\text { Turkish } \\
(\mathrm{n}=226)\end{array}$ \\
\hline Height, cm & $179.6 \pm 0.5$ & $174.0 \pm 0.8^{*}$ & $171.3 \pm 0.5^{*}$ & $167.0 \pm 0.5$ & $160.8 \pm 0.5^{*}$ & $157.8 \pm 0.4^{*}$ \\
\hline Weight, kg & $80.4 \pm 1.0$ & $77.4 \pm 1.3$ & $76.8 \pm 1.2 *$ & $70.3 \pm 0.8$ & $72.4 \pm 1.6$ & $71.7 \pm 0.9$ \\
\hline $\mathrm{BMI}, \mathrm{kg} / \mathrm{m}^{2}$ & $25.0 \pm 0.3$ & $25.6 \pm 0.4$ & $26.2 \pm 0.3 *$ & $25.2 \pm 0.3$ & $28.1 \pm 0.6^{*}$ & $28.9 \pm 0.3^{*}$ \\
\hline Waist circumference, $\mathrm{cm}$ & $95.5 \pm 0.8$ & $93.0 \pm 1.3$ & $94.4 \pm 0.9$ & $86.7 \pm 0.7$ & $93.1 \pm 1.2 *$ & $92.1 \pm 0.8^{*}$ \\
\hline Hip circumference, $\mathrm{cm}$ & $102.6 \pm 0.6$ & $103.0 \pm 0.8$ & $102.2 \pm 0.7$ & $104.0 \pm 0.7$ & $108.1 \pm 1.1^{*}$ & $108.3 \pm 0.7^{*}$ \\
\hline Waist-to-hip ratio & $0.93 \pm 0.01$ & $0.90 \pm 0.01 *$ & $0.92 \pm 0.01$ & $0.83 \pm 0.01$ & $0.86 \pm 0.01 *$ & $0.85 \pm 0.005^{*}$ \\
\hline
\end{tabular}

*Statistically significant difference $(\mathrm{p}<0.05)$ compared to Dutch ethnic group.

${ }^{a}$ Weighted population mean; adjusted for age according to the sex and age distribution in the Amsterdam population.

men had a significantly lower waist-to-hip ratio than Dutch men. Among women a relatively high mean BMI was seen among both Turkish and Moroccan migrant women as compared to ethnic Dutch women. The same was seen in mean waist and hip circumference and waist-to-hip ratio; these were significantly higher among Turkish and Moroccan women than among Dutch women.

In figure 1 prevalence rates for overweight $\left(25 \mathrm{~kg} / \mathrm{m}^{2} \leq\right.$ $\mathrm{BMI}<30 \mathrm{~kg} / \mathrm{m}^{2}$ ), (general) obesity $\left(\mathrm{BMI} \geq 30 \mathrm{~kg} / \mathrm{m}^{2}\right.$ ), abdominal obesity (waist $\geq 102 \mathrm{~cm}$ (men) or $\geq 88 \mathrm{~cm}$ (women)), and central obesity (waist-to-hip ratio $\geq 0.95$ (men) or $\geq 080$ (women)) are presented by ethnic group, separately for men and women. All prevalence rates were adjusted for over-sampling by weighting for age. Prevalence rates for overweight were between 33 and $45 \%$, and prevalence rates for obesity varied between 11 and 16\%. Among women, general obesity, central obesity, and abdominal obesity were much more prevalent than among men in all ethnic groups. Compared to Dutch women general obesity prevalence rates were more than twice as high among Turkish and Moroccan women. Prevalence rates for abdominal obesity were also higher among Turkish and Moroccan women compared to Dutch women. Of all measures for obesity, prevalence rates for central obesity were highest in all ethnic groups, with a majority of women having waist-to-hip ratios larger than 0.80 . No sta- tistically significant differences between ethnic groups in prevalence rates of central obesity were found. A BMI of $25 \mathrm{~kg} / \mathrm{m}^{2}$ or higher was significantly $(\mathrm{p}=0.01)$ more common among Turkish men $(61 \%)$ than among Dutch men $(44 \%)$. The difference in overweight between Moroccan (50\%) and Dutch men was not statistically significant. General obesity $\left(\mathrm{BMI} \geq 30 \mathrm{~kg} / \mathrm{m}^{2}\right)$ prevalence rates did not significantly differ between men with different ethnic backgrounds, neither did prevalence rates for central and abdominal obesity. However among Dutch men abdominal obesity was much more prevalent than general obesity while among Turkish and Moroccan men there were no significant differences.

The association between BMI and waist circumference or waist-to-hip ratio might differ between ethnic groups. To analyse this, linear regression analyses were performed with waist circumference and waist-to-hip ratio as dependent variables and BMI, ethnicity and age as covariates. Because of a significant interaction effect (among women) between BMI and ethnicity, all analyses were stratified by sex. The resulting regression lines for each ethnic group are shown in figure 2. Dutch men had an overall higher waist circumference and waist-tohip ratio in relation to their BMI than migrant men. In women a significant interaction effect between BMI and ethnicity was found in Moroccan and Turkish women in relation to waist circumference and in relation to waist-to-hip ratio in Turkish 


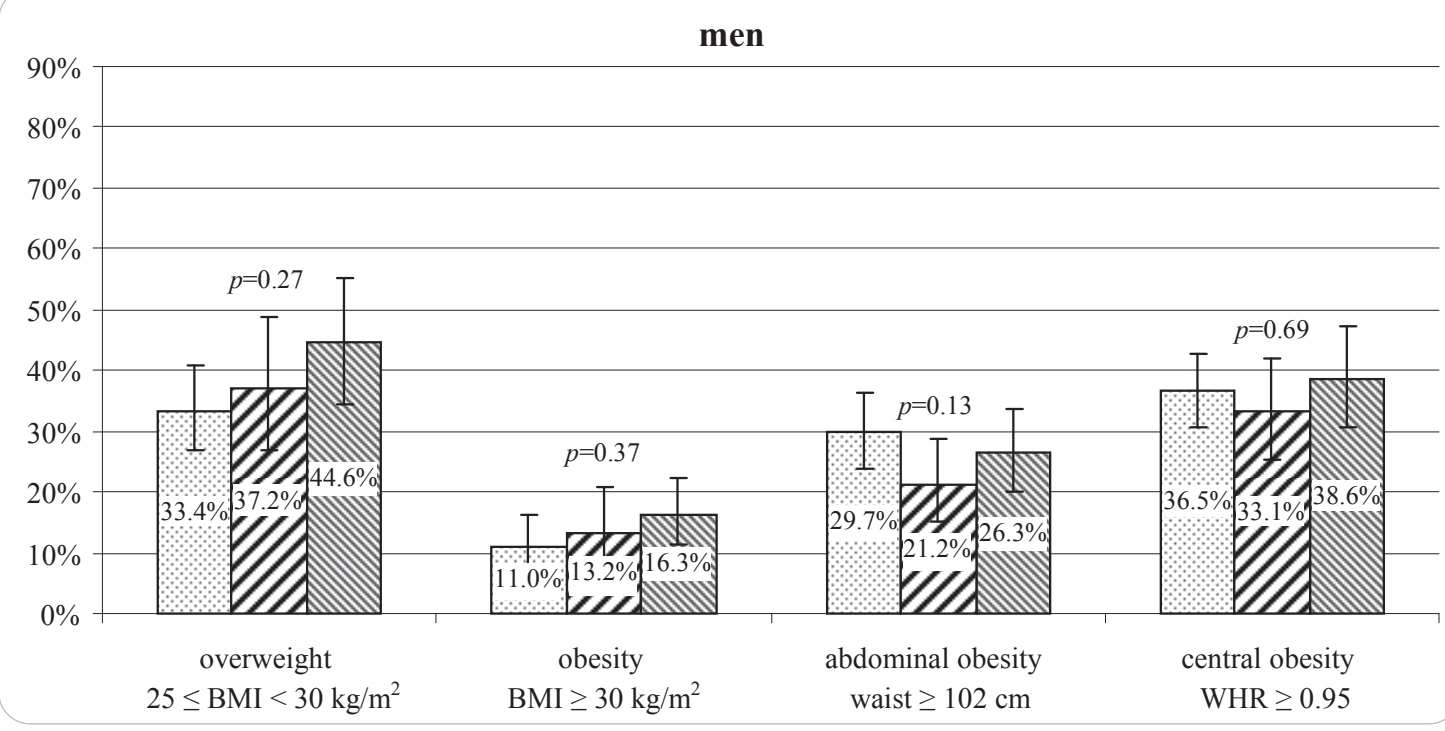

Fig. 1. Overweight, obesity, abdominal obesity and central obesity, by ethnic group. $\mathrm{p}=\mathrm{p}$ value of $\chi^{2}$-test for significance of ethnic differences; waist $=$ waist circumference; WHR = waist-to-hip ratio. ${ }^{\text {aprevalence rates }}$ adjusted for age according to the age distribution in the Amsterdam population.

${ }^{b}$ Vertical (error) bars show $95 \%$ confidence intervals

$\square$ Dutch;

Woroccan;

Turkish.

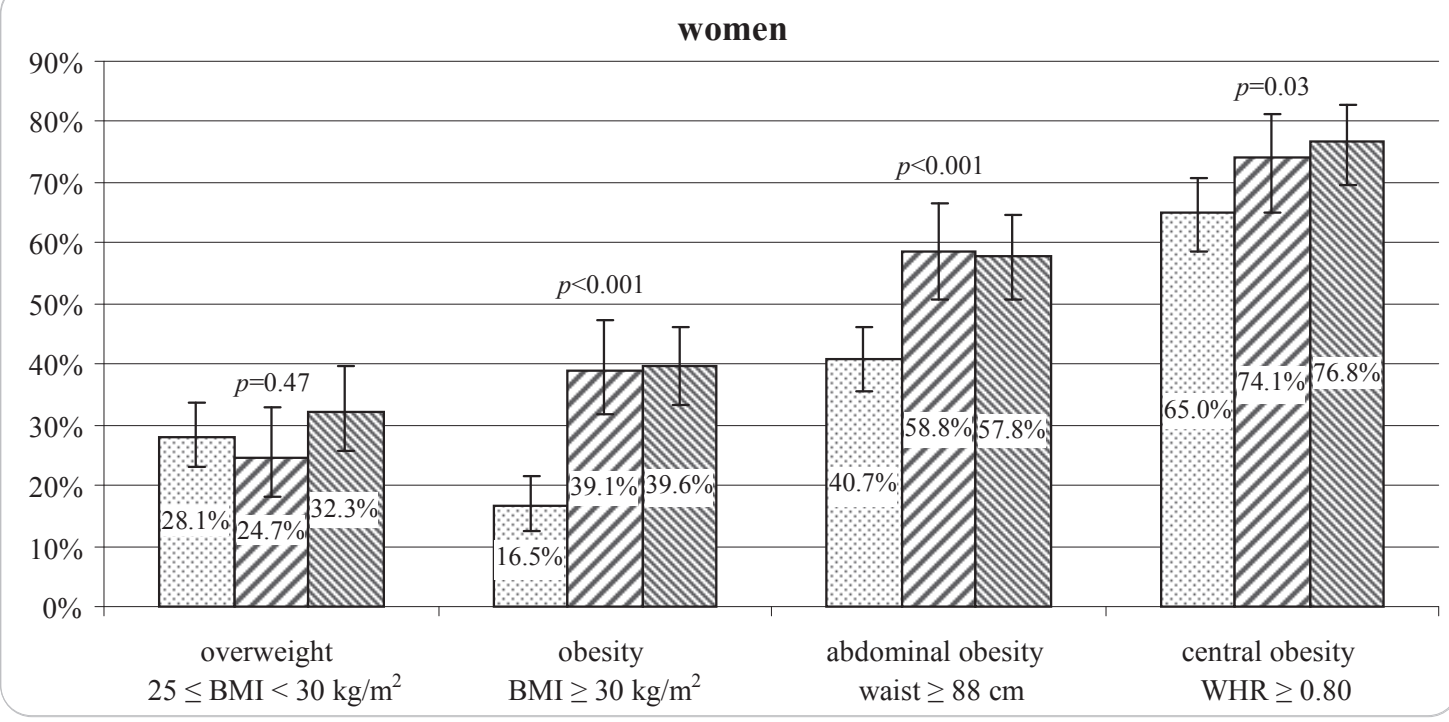

women only, as compared to Dutch women. Turkish and Moroccan women with a lower BMI had a (slightly) higher waist circumference than their Dutch counterparts. However, migrant women with a relatively high BMI had a (slightly) lower waist circumference than Dutch women. Turkish women with a lower BMI had a (slightly) higher and Turkish women with a relatively high BMI had a (slightly) lower waist-to-hip ratio than their Dutch counterparts.

As shown in table 3, ethnic differences in obesity prevalence were not the same across all socio-economic groups. Obesity prevalence rates were much higher in Turkish and Moroccan migrants with a low educational level as compared to Dutch people with the same level of education, but not in migrants with higher educational levels. Turkish migrants with a relatively low income had a higher prevalence of obesity than Dutch people with the same income level. In contrast, in the Moroccan ethnic population obesity prevalence rates were relatively high in all income groups. Unemployment also had a boosting effect on ethnic differences in prevalence rates of obesity in Turkish and Moroccan migrants compared to the Dutch.

In table 4 the effect of the investigated SES indicators on the association between ethnicity and BMI, controlling for age, is shown. Controlling for individual SES indicators did not eliminate ethnic differences in BMI; BMI remained relatively high in Turkish and Moroccan migrants as compared to their Dutch counterparts. Controlling for several SES indicators, however, did have an attenuating effect on ethnic differences in BMI. In all groups educational level and unemployment (especially among men) did have a substantial, attenuating effect on the magnitude of the effect of ethnicity on differences in BMI. In Moroccan men and Turkish women income 

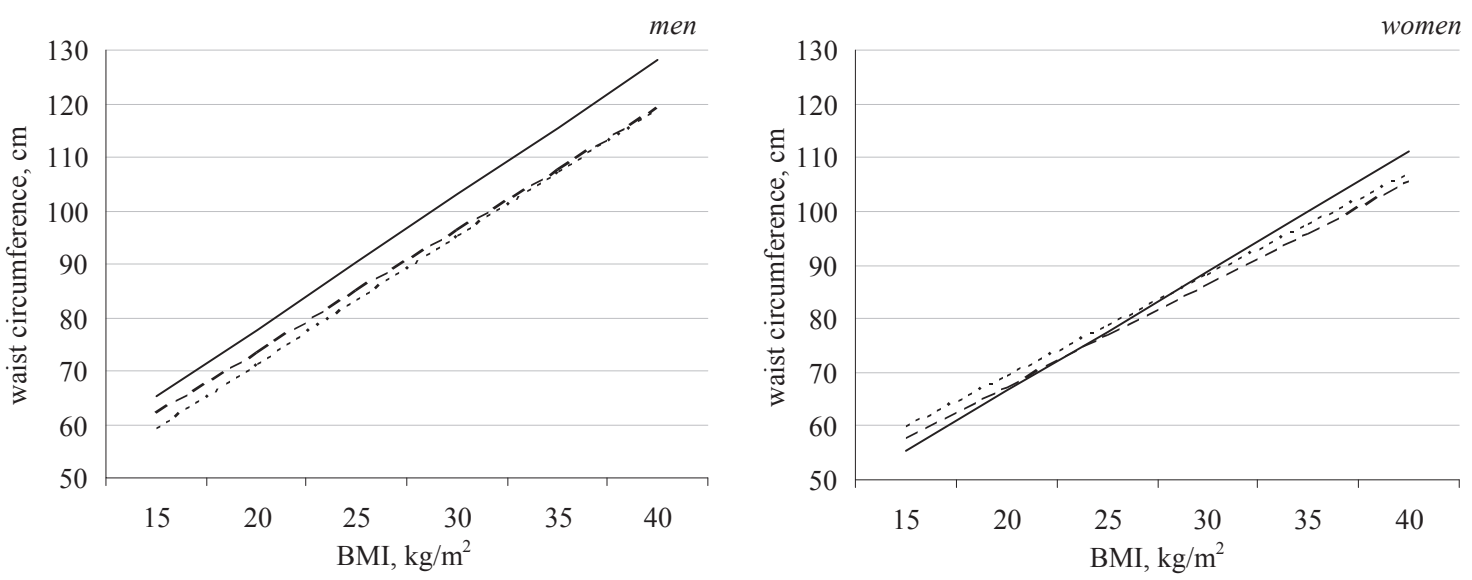

Fig. 2. Multivariate linear regression analysis $^{\mathrm{a}}$ of the association between BMI and waist circumference / waist-tohip ratio, by ethnic group.

${ }^{a}$ Dependent variable: waist circumference / waist-to-hip ratio, models adjusted for age.

- Dutch;

..... Moroccan;

---- Turkish.
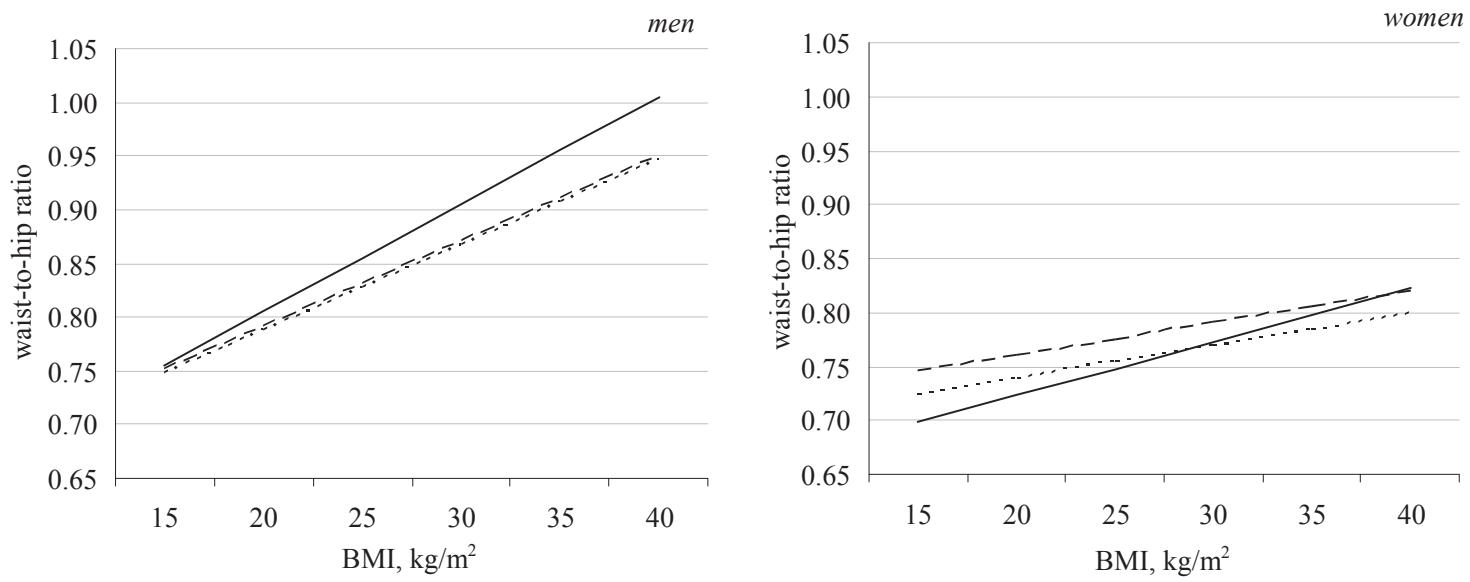

Table 3. Obesity by SES, in Dutch, Turkish and Moroccan ethnic groups ${ }^{\mathrm{a}}$

\begin{tabular}{|c|c|c|c|c|c|c|}
\hline & \multicolumn{2}{|c|}{ Dutch } & \multicolumn{2}{|c|}{ Moroccan } & \multicolumn{2}{|c|}{ Turkish } \\
\hline & $\mathrm{n}$ & $\%(95 \% \mathrm{CI})$ & $\mathrm{n}$ & $\%(95 \% \mathrm{CI})$ & $\mathrm{n}$ & $\%(95 \% \mathrm{CI})$ \\
\hline Total & 510 & $13.8(11.1-17.2)$ & 353 & $26.2(21.5-31.6)$ & 422 & $27.9(23.8-32.4)$ \\
\hline \multicolumn{7}{|l|}{ Educational level } \\
\hline High & 157 & $6.7(3.5-12.2)$ & 23 & $19.0(7.0-42.2)$ & 27 & $7.0(2.0-21.2)$ \\
\hline Medium & 253 & $16.9(12.6-22.4)$ & 98 & $15.7(8.9-26.2)$ & 128 & $12.5(8.0-19.0)$ \\
\hline Low & 93 & $21.9(13.7-33.1)$ & 220 & $39.1(33.0-45.6)^{* * *}$ & 254 & $43.6(36.7-50.7)^{* *}$ \\
\hline \multicolumn{7}{|l|}{ Income $^{b}$} \\
\hline Standard or above standard & 295 & $11.7(8.4-16.0)$ & 50 & $28.0(17.1-42.4)^{* * *}$ & 87 & $18.4(11.9-27.4)$ \\
\hline Below standard & 142 & $17.8(12.0-25.6)$ & 200 & $25.3(20.0-31.4) * *$ & 262 & $34.4(29.1-40.1)^{* *}$ \\
\hline \multicolumn{7}{|l|}{ Financial situation $^{\mathrm{b}}$} \\
\hline Able to have money left & 299 & $13.0(9.4-17.7)$ & 51 & $22.6(11.4-39.7)$ & 42 & $20.6(11.0-35.3)$ \\
\hline Can just get by & 174 & $16.5(11.7-22.6)$ & 178 & $29.1(22.7-36.5)^{* * *}$ & 274 & $30.6(25.0-36.7)^{* *}$ \\
\hline Has to use savings or go into debt & 21 & $14.5(7.9-25.1)$ & 93 & $30.2(20.5-42.0) *$ & 95 & $29.8(22.3-38.5) *$ \\
\hline \multicolumn{7}{|l|}{ Employment status } \\
\hline Employed or retired (respondent) & 414 & $13.1(10.0-16.9)$ & 149 & $19.8(12.8-29.4)$ & 172 & $18.8(13.9-24.9)$ \\
\hline Unemployed (respondent) & 87 & $18.5(11.9-27.6)$ & 189 & $32.8(26.9-39.2)^{*}$ & 227 & $35.5(29.0-42.5)^{* *}$ \\
\hline Employed or retired (main breadwinner) & 414 & $13.7(10.6-17.7)$ & 178 & $23.9(17.3-32.1)^{* *}$ & 204 & $20.5(15.8-26.3)^{*}$ \\
\hline Unemployed (main breadwinner) & 66 & $18.1(11.9-26.6)$ & 139 & $37.0(29.0-45.9)^{* * *}$ & 164 & $36.0(27.9-44.9)^{*}$ \\
\hline
\end{tabular}

${ }^{a}$ Adjusted for sex and age according to the sex and age distribution in the Amsterdam population.

${ }^{\mathrm{b}}$ On household level.

${ }^{\circ}$ Unemployed, receiving social assistance or invalidity benefits.

$* \mathrm{p}<0.05, * * \mathrm{p}<0.01$ statistically significant difference compared to Dutch ethnic group. 
Table 4. Multivariate linear regression analysis of the association between ethnicity and BMI

\begin{tabular}{|c|c|c|c|c|c|c|}
\hline & \multicolumn{3}{|l|}{ Men } & \multicolumn{3}{|c|}{ Women } \\
\hline & Dutch & Moroccan & Turkish & Dutch & Moroccan & Turkish \\
\hline & & B $(95 \%$ CI $)$ & B $(95 \%$ CI $)$ & & B (95\% CI) & B $(95 \%$ CI $)$ \\
\hline Model $1^{\mathrm{a}}$ & ref & $1.30(0.52-2.08)^{* *}$ & $2.56(1.79-3.34) * * *$ & ref & $4.50(3.46-5.53) * * *$ & $5.48(4.54-6.41)^{* * * *}$ \\
\hline Model 2: educational level & ref & $0.95(0.05-1.84)^{*}$ & $2.28(1.41-3.16)^{* * *}$ & ref & $3.23(2.09-4.38) * * *$ & $3.99(2.92-5.06)^{* * *}$ \\
\hline Model $3^{\text {b}: ~ i n c o m e ~ l e v e l ~}$ & ref & $1.11(0.08-2.15)^{*}$ & $2.54(1.57-3.50)^{* * *}$ & ref & $4.41(3.10-5.72)^{* * *}$ & $4.84(3.71-5.97)^{* * *}$ \\
\hline Model $4^{\text {b }}$ : financial situation & ref & $1.23(0.30-2.16)^{*}$ & $2.63(1.71-3.55)^{* * *}$ & ref & $4.20(3.04-5.35)^{* * *}$ & $4.96(3.88-6.04)^{* * *}$ \\
\hline $\begin{array}{l}\text { Model } 5^{\text {b }} \text { : unemployment } \\
\text { (respondent) }\end{array}$ & ref & $1.17(0.36-1.98)^{* *}$ & $2.28(1.47-3.10)^{* * *}$ & ref & $3.64(2.49-4.78)^{* * *}$ & $4.64(3.61-5.68)^{* * *}$ \\
\hline $\begin{array}{l}\text { Model } 6^{\text {b }} \text { : unemployment } \\
\text { (main breadwinner) }\end{array}$ & ref & $1.09(0.26-1.93)^{*}$ & $2.17(1.33-3.02)^{* * *}$ & ref & $4.10(2.95-5.23)^{* * *}$ & $4.74(3.70-5.78)^{* * *}$ \\
\hline Model $7^{c}$ : all indicators of SES & ref & $0.64(-0.54$ to 1.82$)$ & $1.91(0.76-3.06)^{* *}$ & ref & $2.71(1.22-4.21)^{* * *}$ & $3.43(2.06-4.80)^{* * *}$ \\
\hline
\end{tabular}

B ( $95 \%$ CI): Regression coefficient for ethnicity with $95 \%$ confidence interval.

$* \mathrm{p}<0.05, * * \mathrm{p}<0.01, * * * \mathrm{p}<0.001$ statistically significant difference compared to Dutch ethnic group.

${ }^{a}$ Dependent variable (y): BMI, model adjusted for age.

${ }^{b}$ Models 2-6: Model 1 additionally adjusted for [variable].

${ }^{c}$ Model 7: Model 1 additionally adjusted for educational level, income, financial situation, unemployment (respondent), unemployment

(main breadwinner).

level also seemed to be a relevant factor in explaining ethnic differences between them and their Dutch counterparts. After controlling for all SES indicators together, ethnicity was no longer a significant factor in Moroccan men, indicating that SES factors were accountable for (almost) all of the ethnic differences in BMI between Dutch and Moroccan men. Although controlling for SES indicators did have an attenuating effect on $\beta$ for ethnicity in the Turkish group and Moroccan women, ethnicity remained a significant factor.

\section{Discussion}

This study shows high prevalence rates of overweight and obesity among Turkish and Moroccan migrants in the Netherlands as compared to the Dutch. The prevalence of general obesity is especially high among migrant women; more than twice as high when compared to Dutch women.

In studies performed among adults (20 years and older) living in Turkey prevalence rates for obesity were somewhat lower than the rates found in our study. In the Turkish Diabetes Epidemiology Study a prevalence of obesity of $22 \%$ was observed [17], and a study performed by Erem et al. [18] among adults found an overall prevalence rate of $24 \%$ for obesity. In both studies prevalence rates were higher among women than among men $[17,18]$. Even if obesity prevalence rates from these studies in Turkey might have been slightly lower than the rates in our study, the prevalence of obesity among these migrant groups in the Netherlands is still lower than that found in Norway. In a Norwegian study among Turkish migrants, the obesity prevalence was $25 \%$ among men and 51\% among women aged $30-60$ years [19].
In Morocco, the most recent national survey in 2000 showed that $13 \%$ of individuals aged 20 years and older were obese (19\% among women and 7\% among men) [20]. We observed a much higher prevalence of obesity among Moroccan migrants, especially among women. Part of this might be explained by our urban setting. In Morocco prevalence rates are also higher in urban areas.

In a recent Dutch study, Cornellise-Vermaat and van den Brink [6] found the prevalence of obesity, based on selfreports, to be $11 \%$ in Turkish migrant men, $17 \%$ in Turkish women, $10 \%$ in Moroccan men, and $11 \%$ in Moroccan women. In our study we found much higher prevalence rates. The obesity prevalence among native Dutch participants was also lower than in our study. These lower rates in the study by Cornellise-Vermaat and van den Brink [6] are possibly due to the use of self-reports instead of measurements of body height and weight [21]. Furthermore, the response rate in their study was low $(23.4 \%)$, and highly educated immigrants and nonworking Dutch women were over-represented, which might indicate that the sample was not representative of the total Dutch population [6].

In Norway, Kumar et al. [19] found that, despite a relatively high mean BMI among Turkish men $\left(27.9 \mathrm{~kg} / \mathrm{m}^{2}\right)$ and women $\left(30.7 \mathrm{~kg} / \mathrm{m}^{2}\right)$, they did not have a correspondingly high waist-to-hip ratio. In our study, we found no statistically significant differences in any of the measures for obesity between men of Dutch, Turkish and Moroccan descent. Only in women, general obesity and abdominal obesity are significantly more prevalent in the Turkish and Moroccan migrant population as compared to their Dutch counterparts. Central obesity is common in all women, with a majority of women having a high waist-to-hip ratio $(>0.80)$, regardless of ethnic 
background. However, when further investigating the relation between excess body fat and body fat distribution, we were able to show that the relation between BMI and waist circumference is not the same for each ethnic group. Although the mean waist circumference is relatively high in Turkish and Moroccan women compared to Dutch women, especially in women with a relatively low BMI, their gain in waist circumference, when their BMI increases, is relatively low compared to Dutch women. Compared to the Dutch and when taking into account their BMI, migrant men had a relatively low waist circumference and waist-to-hip ratio.

It is known that in highly developed countries, SES is strongly and inversely associated with obesity [7-9]. One of the aims in this study was to gain insight into the effect of several indicators of SES on ethnic differences in the prevalence of obesity. We have shown that ethnic differences in obesity prevalence are not the same in all socio-economic groups. And, although none of the investigated individual socio-economic factors can completely account for all of the differences, educational level and unemployment, especially among men, seem to be important factors in explaining ethnic differences in BMI. These factors have a substantial and attenuating effect on differences in BMI between the Moroccan and Turkish populations and the Dutch population. A possible explanation for this is that educational level may be positively associated with the extent to which someone is influenced by social standards and health messages, and thus be negatively associated with obesity risk [9]. Furthermore, unemployment might cause stress and in general deteriorate health and therefore increase the risk of obesity [22]. However the relation between SES and obesity is a complex, bidirectional one, and other factors such as heredity possibly play a role [23].

When interpreting the results of our study, its strengths and limitations should be taken into account. A clear strength of the present study is that we were able to assess data on body weight and height via physical examination. In several studies $[6,12,13]$, prevalence rates of obesity among Turkish and Moroccan migrants were based on self reports, which is known to lead to underestimation of the true problem of obesity and overweight [21]. In our study we used measurements of body weight and height as well as waist and hip circumference to assess prevalence rates of (central and abdominal) obesity.

Another important strength is the inclusion of a large sample of two well-defined ethnic minority groups, Turks and Moroccans, that could be compared to a Dutch population sample from the same study.

An unavoidable potential source of bias could have resulted from the relatively low participation rate $(45 \%)$. Nonetheless, the response rate is comparable to that of several other large surveys in the Netherlands indicating that any systematic bias is unlikely $[13,24,25]$. In addition, the number of individuals who did not receive the survey invitation is likely to be high, due to the high mobility of the Amsterdam population and incorrect residential information in the municipal population register (between 7.5 and $15 \%$ according to a recent investigation [26]). This may have had a negative effect on our response rate. To correct for over-sampling and nonresponse bias, our data were weighted for age and sex group. Altogether, we consider the sample to be representative of the Amsterdam population.

Several measures for overweight and body composition exist. In our study we measured relative body weight, waist and hip circumference. Other measurements are available to gain more insight into body composition and more precisely locate fat storages, such as dual-energy X-ray absorptiometry (DXA) and computed tomography (CT) [27]. However, including these measurements in a general health survey, is not feasible. Nonetheless, BMI and waist circumference are widely accepted measures, and waist circumference has been reported to be a better correlate of cardiovascular disease than other anthropometric indices [2, 3, 28].

In conclusion, we found relatively high prevalence rates of overweight and obesity among Turkish and Moroccan women and Turkish men. However, the association between BMI and waist circumference seems to differ across ethnic groups. Among women, abdominal obesity is more common in the Turkish and Moroccan than in the Dutch group. However, Turkish and Moroccan women with a lower BMI have a higher waist circumference, but migrant women with a relatively high BMI have a lower waist circumference compared to Dutch women. In Turkish women the same pattern was seen for waist-to-hip ratio. Among Turkish men, overweight is more common than among their Dutch counterparts, however, they do not have a higher waist circumference or waistto-hip ratio than the Dutch. Moreover, when taking into account their relatively high BMI, they have a lower waist circumference and waist-to-hip ratio, indicating that Turkish men have a more favourable fat distribution with less abdominal fat than Dutch men.

However, the prevalence rate of overweight and obesity is still relatively high among Turkish and Moroccan migrants, especially women. Of all investigated socio-economic factors, educational level and employment status, the latter mainly among men, seem to be most important in explaining ethnic differences in BMI. To diminish ethnic differences in obesity prevalence, health promotion should also be aimed at diminishing socio-economic inequalities.

\section{Disclosure Statement}

The authors declare no conflicts of interest. 


\section{References}

1 Lopez AD, Mathers CD, Ezzati M, Jamison DT, Murray CJL (eds): Global Burden of Disease and Risk Factors. Washington DC, The World Bank, 2006.

2 Lean MEJ, Han TS, Morrison CE: Waist circumference as a measure for indicating need for weight management. BMJ 1995;311:158-161.

3 Ketel IJG, Volman MNM, Seidell JC, Stehouwer CDA, Twisk JW, Lambalk CB: Superiority of skinfold measurements and waist over waist-tohip ratio for determination of body fat distribution in a population based cohort of Caucasian Dutch adults. Eur J Endocrinol 2007;156:655-661.

4 Yusuf S, Hawken S, Ôunpuu S, Bautista L, Franzosi MG, Commerford P, Lang CC, Rumboldt Z, Onen CL, Lisheng L, Tanomsup S, Wangai P Jr, Razak F, Sharma AM, Anand SS: Obesity and the risk of myocardial infarction in 27,000 participants from 52 countries: a case-control study. Lancet 2005;366: 1640-1649.

5 Brussaard JH, Erp-Baart MA van, Brants HAM, Hulshof KFAM, Löwik MRH: Nutrition an health among migrants in the Netherlands. Public Health Nutr 2001;4:659-664.

6 Cornelisse-Vermaat JR, van den Brink HM: Ethnic differences in lifestyle and overweight in the Netherlands. Obesity 2007:15:483-493.

7 Brunner EJ, Marmot MG, Nanchahal K, Shipley MJ, Stansfeld SA, Juneja M, Alberti KGMM: Social inequality in coronary risk: central obesity and the metabolic syndrome. Evidence from the Whitehall II study. Diabetologia 1997:40:1341-1349.

8 Molarius A, Seidell JC, Sans S, Tuomilehto J, Kuulasmaa K: Educational level, relative body weight and changes in their association over 10 years: an international perspective from the WHO MONICA project. Am J Public Health 2000;90:1260-1268.

$\checkmark$ McLaren L: Socioeconomic status and obesity. Epidemiol Rev 2007;29:29-48.
10 Uitewaal PJM, Manna DR, Bruijnzeels MA, Hoes AW, Thomas S: Prevalence of type 2 diabetes mellitus, other cardiovascular risk factors, and cardiovascular disease in Turkish and Moroccan immigrants in North West Europe: a systematic review. Prev Med 2004;39:1068-7106.

11 Dienst Onderzoek en Statistiek: Amsterdam in figures (in Dutch). Amsterdam, Dienst Onderzoek en Statistiek, Gemeente Amsterdam, 2006.

12 Dijkshoorn H, Nierkens V, Nicolaou M: Risk groups for overweight and obesity among Turkish and Moroccan migrants in the Netherlands. Public Health 2008;122:625-630.

13 Reijneveld SA: Reported health, lifestyles, and use of health care of first generation immigrants in the Netherlands: do socioeconomic factors explain their adverse position? J Epidemiol Community Health 1998;52:298-304.

14. Agyemang C, Ujcic-Voortman J, Uitenbroek D, Foets M, Droomers M: Prevalence and management of hypertension among Turkish, Moroccan and native Dutch ethnic groups in Amsterdam, the Netherlands: the Amsterdam Health Monitor Survey. J Hypertens 2006;24:2169-2176.

15 Ujcic-Voortman JK, Schram MT, Jacobs-van der Bruggen MA, Verhoeff AP, Baan CA: Diabetes prevalence and risk factors among ethnic minorities. Eur J Public Health 2009;19:511-515.

16 World Health Organization: Obesity: Preventing and Managing the Global Epidemic. WHO Technical Report 894. Geneva, WHO, 2000.

17 Satman I, Yilmaz T, Sengül A, Salman S, Salman F, Uygur S, Bastar I, Tütüncü Y, Sargin M, Dinççag N, Karsidag K, Kalaça S, Özcan C, King H: Populationbased study of diabetes and risk characteristics in Turkey: results of the Turkish diabetes epidemiology study (TURDEP). Diabetes Care 2002;25:1551-1556.

18 Erem C, Arslan C, Hacihasanoglu A, Deger O, Topbaș M, Ukinc K, Önder Ersöz H, Telatar M: Prevalence of obesity and associated risk factors in a Turkish population (Trabzon city, Turkey). Obes Res 2004;12:1117-1127.
Kumar BN, Meyer HE, Wandel M, Dalen I, Holmboe-Ottesen G: Ethnic differences in obesity among immigrants from developing countries, in Oslo, Norway. Int J Obes 2006;30:684-690.

20 Tazi MA, Abir-Khalil S, Chaouki N, Cherqaoui S, Lahmouz F, Sraïri JE, Mahjour J: Prevalence of the main cardiovascular risk factors in Morocco: results of a National Survey, 2000. J Hypertens 2003;21: 897-903.

21 Visscher TLS, Viet L, Kroesbergen I, Seidell JC: Underreporting of BMI in adults and its effect on obesity prevalence estimations in the period 1998 to 2001. Obesity 2006;14:2054-2063.

22 Laitinen J, Power C, Ek E, Sovio U, Järvelin MR Unemployment and obesity among young adults in a northern Finland 1966 birth cohort. Int J Obes 2002;26:1329-1338.

23 Stunkard AJ: Obesity and socioeconomic status: a complex relation. N Eng J Med 1993;329:1036-1037.

24 Agyemang C, Denktas S, Bruijnzeels M, Foets M: Validity of the single-item question on self-rated health status in Turkish and Moroccan elderly versus native Dutch elderly in the Netherlands. Public Health 2006;120:543-550.

25 Uiters E, Devillé WLJM, Foets M and Groenewegen PP: Use of health care services by ethnic minorities in The Netherlands: do patterns differ? Eur J Public Health 2006;16:388-393.

26 Slot J, Janssen M: Measurement of actual quality Municipal Population Register (in Dutch). Amsterdam, Dienst Onderzoek en Statistiek, Gemeente Amsterdam, 2006.

27 Glickman SG, Marn CS, Supiano MA, Dengel DR: Validity and reliability of dual-energy X-ray absorptiometry for the assessment of abdominal adiposity. J Appl Physiol 2004;97:509-514.

28 Seidell JC, Pérusse L, Després JP, Bouchard C: Waist and hip circumferences have independent and opposite effects on cardiovascular disease risk factors: the Quebec Family Study. Am J Clin Nutr 2001;74:315-321. 